\title{
From Gravitational Machine to Universal Habitat: The Drainage Basin and Amphibious Futures in the Chao Phraya Delta, Thailand
}

\author{
ATSURO MORITA \\ OSAKA UNIVERSITY
}

\begin{abstract}
This paper elucidates the development of the drainage basin model, one particular frame for capturing the relative motion between water and land, by highlighting the parallel developments between scientific notion and water management infrastructures. Facilitating a continuous movement back and forth between science and infrastructure, the drainage basin allows for the revelation of unexpected forms of relatedness and has played an important role in the emergence of a form of relational morality. To make this argument, this paper focuses on the Chao Phraya Delta in Thailand. While located in the periphery of the centers of modern science, the delta holds significance as a place where colonial hydrological technoscience and indigenous development intersected. The encounter between the two has resulted in a new vision of the city as a waterscape, a sort of drainage basin that connects natural, social and economic processes through numerous, complex water flows.
\end{abstract}

\section{Keywords}

drainage basin; hydrology; urban design

\section{Introduction}

Although water technologies such as irrigation and coastal infrastructures have long been of interest to anthropology (Geertz 1972; Tanabe 1994) and science and technology studies (STS) (Bijker 2007), the past ten years have seen a resurgent interest in water in both disciplines (Helmreich 2011; Barnes and Alatout 2012; Carse 2012; Krause and Strang 2016). This heightened focus partly reflects growing concerns about governance of the environment, resources and infrastructures, in which water plays a crucial role. As Barnes and Alatout have written water: "quenches thirsty, sustains crops, generate power, cools industry, carries ship, disposes waste, and maintain ecosystems" (2012: 483). Because of these multiple roles, the governance of water has wide-ranging impact. Thus, STS scholars have explored how the modernization of water

\footnotetext{
. Atsuro Morita, Email: atsmrt@me.com

Copyright (C) 2017 (Atsuro Morita). Licensed under the Creative Commons Attribution Non-commercial No Derivatives (by-nc-nd). Available at estsjournal.org.
} 
management has brought about "new forms of governance, and newly emergent processes of state formation that administer both water use practices and the water technologies designed to support them" (Bakker 2012: 618).

Some of these new studies engage with water as more than an exclusively empirical issue. Thus, scholars have increasingly become aware of the capacity of water to provide metaphors for elusive social worlds, and as offering heuristics for new conceptualizations (Krause and Strang 2016). Recently, for example, Wiebe Bijker (2012) proposed "water cultures" as concept for STS. As an extension of his earlier notion of "technological cultures," Bijker's water cultures would heuristically draw attention to the mutual constitution of society and water.

In a similar vein, the anthropologists Stefan Helmreich argues material-semiotic effects of seawater as a theory machine, a notion originally coined by Peter Galison. In line with Mary Hesse's (1970) classic argument on models and analogies in science, Galison (2003) has shown that machines contemporary with Einstein and Poincaré, such as the electro-coordinated clocks of railroad networks, provided heuristic models that these physicists used to frame their problems. Galison refers to such objects as "theory machines," defined as objects "in the world that stimulates a theoretical formation." (132) Taking over this idea, Helmreich (2011) has analyzed the anthropological and social scientific use of seawater as a theory machine for modeling social and cultural phenomena. Thus, for example, notions such as "global flows" or "fluid identities," have been used to rethink space, geography and connectivity. Indeed, Helmreich notes, watery metaphors such as flow, liquidity and foam are widely used to create alternative imaginaries of the world. As an alternative to land-based views of history, for example, oceanization entails "a reorientation toward the seas as a translocally connecting substance" (137).

However, immediately after examining these liquid social metaphors, Helmreich turns to the scientific practice of oceanographic simulation to question the idea that they are determined by the material qualities of water (see also the introduction to this thematic section). As every STS scholar should know, what water is, is neither self-evident nor given. The behavior of seawater, for example, becomes visible through complex numerical simulations that not only draws on a vast amount of data but also embeds a certain theory of hydrodynamics. Thus, when seawater operates as a theory machine for reconceiving sociality, it happens through social practice. Resonating with recent experiments with lateral analysis in anthropology and STS (Maurer 2004; Morita 2014; Gad and Jensen 2016), Helmreich (2011: 138) therefore notes his interest:

in how simultaneously to employ water as a theory machine, when useful, and to treat both water and theories as things in the world. I think of this approach as operating "athwart theory": that is, as tacking back and forth between seeing theories as explanatory tools and taking them as phenomena to be examined. Such an account does not separate meaning and materiality.

This "tacking back and forth" is indeed often necessary in order to track watery concepts, some of which rapidly change shape from scientific notions to evocative metaphors to things in the world. Given this transformational proclivity, those who try to follow the displacement of watery concepts often inadvertently traverse the boundary between the conceptual and the 
empirical, the semiotic and the material. The drainage basin, which has been established as a predominant frame for understanding land-water relationships in hydrology, geomorphology, ecology and environmental management, vividly exemplifies this boundary-defying tendency.

\section{The Drainage Basin}

A drainage basin is the area where water from rainfall flows into a single river. Because (a significant part of) rainfall flows on land surfaces from higher to lower areas, the runoff from a given area eventually gathers in a river that flows downstream towards the sea. While "drainage basin" and "river basin" are most often used in scientific papers and textbooks in hydrology, synonyms such as "catchment" and "watershed" are also used."

In European history, drainage basins have long been used to demarcate regions because they are so readily identifiable. This pre-modern usage served as a basis for the eventual development of the scientific notion of drainage basin (Clifford 2011). However, though taking different forms, the significance of the drainage basin as a geographic or water management unit was also recognized in other parts of the world (Molle 2009).

The European notion of drainage basin gradually gained scientific significance since the 17th century, through successive efforts to estimate the relation between rainfall and river discharge. At that time, it was realized that the size of the drainage basin was an important element in predicting the increase of river flows from rainfall. As new measurements and calculation methods were introduced in the 19th to early 20th century, the relation between rainfall, drainage basin area and river discharge was continuously elaborated and refined (Clifford 2011). Parallel to this development, Europeans since the mid-18th century gradually developed the idea of the drainage basin as a natural geographic unit for administration and economic planning (Molle 2009).

Since the late 20th Century, the importance of the drainage basin has gone beyond the boundaries of hydrology and even gained symbolic significance in environmental management and activism. For example, the inaugural note of Watershed: People's Forum on Ecology, an international journal for environmental activism based in Bangkok, defines its scope as follows:

In the broader ecological sense, the term watershed includes not only the land and water but the mountains and forest, flood plains and valleys, as well as the communities of

" These words have slightly different connotations. Molle (2009: 484) notes that "tributary sub-basins or basins more limited in size (typically from tens of square kilometers to 1000 square kilometers) are often called watersheds (in American English), while catchment is frequently used in British English as a synonym for river basins, watershed being more narrowly defined as the line separating two river basins."

${ }^{3}$ For example, the drainage basin served as a mold for political organization in mountainous Southeast Asia, an area that stretches from Yunnan in China to Assam in India and including Laos, the northern parts of Thailand, Vietnam and Myanmar. In this area, Tai peoples, who speak a variety of languages related to Thai, almost uniformly inhabit intermountain basins where they built small-scale irrigation systems for rice cultivation. Their political organization ("muang" in Thai) coincides with the range of a basin and irrigation infrastructure (Tanabe 1994). These basin-based Tai polities played a central role in structuring much wider forms of multi-ethnic political organization in the area (Leach 1954). 
plants, animals and people who live there. (Watershed 1995: 2)

Not only is the watershed a very encompassing notion, it also invokes a particular approach to the environment:

A watershed approach can be an alternative process of learning, of learning [...] by awareness of the interaction and interdependency of people and nature, the blending (and clashing) of cultural, ecological, political and economic forces [...] At the heart of this approach is empathy, a respect for life downstream and in the mountain forests where water springs. (2-3)

The expansion and transformation of the watershed from its original hydrological definition is fascinating. While originating as a technical notion to measure water flow, it has become a holistic and evocative notion that connects various elements from hydrology and ecology to local culture and democratic participation. Indeed, the journal editor argues that the watershed points to an alternative to extractive modes of development as currently practiced in the region. Just like watery metaphors in social science points toward novel conceptualizations, the watershed points to alternative futures.

In this paper, I track how the drainage basin was gradually transformed through a transversal movement that moved across several disciplines and cut across the boundaries of the material and the semiotic. I trace this transformation by travelling with the drainage basin from hydraulic engineering and hydrology to geomorphology, river ecology and, eventually, to urban planning. During this pursuit, I focus on how a particular framework of land-water relations has worked both materially and theoretically as a machine that shaped wider social and environmental relations. Thus, I delineate some close links between the scientific concept of the drainage basin and water infrastructures, which are huge machines to control water. As I show, these infrastructures have provided a framework for conceptualizing water-land interactions. They have thus significantly contributed to the development of the scientific notion of drainage basin. I further show that the drainage basin has presently gained its own momentum and started to counteract the design of water infrastructures that nurtured its own development to begin.

In order to elucidate this complex back and forth, I focus in particular on the Chao Phraya Delta in Thailand, a rather peculiar location in the international network of hydrology and hydraulic engineering. The history of the delta exemplifies a significant change in the broader political geography that gives varied significance to river basins in the global north and south. This shift, and the transformation of the concept of the drainage basin have gone hand in hand, both illustrating the emergence of new watery notions as indexing alternative modes of organizing infrastructures and societies. My ethnographic encounter with water management infrastructures in the Chao Phraya Delta thus provides a situated viewpoint to trace these parallel shifts and elucidate the emergence of a particular capacity to evoke an amphibious future. 


\section{Gravitational Machine}

On February 7, 1957, the King of Thailand, Bhumibol Adulyadej, made a speech to celebrate the opening of the Chao Phraya Dam, a barrage on which the entire Greater Chao Phraya Irrigation Project hinged. The project was one of the largest in Asia at the time, covering the major part of the Chao Phraya Delta, an area of 11,600 square kilometers. In his speech, the King emphasized the government's continuous efforts to install irrigation ever since the reign of the legendary King Chulalongkorn (1853-1910), who had laid the foundation of the modern Thai state. The dam, too, had been planned during the reign of King Chulalongkorn but had been shelved for almost 50 years due to lack of financial resources (Brummelhuis 2005).

The story of the Chao Phraya Dam is particularly telling because it portrays a normative vision of river flow that a particular design of infrastructure embodies. As we shall see this normative vision entangles the way scientists and engineers see and conceptualize forms of land water interaction.

As originally conceived by the Dutch irrigation engineer Homan van der Heide, the main aim of the Chao Phraya Dam was to deliver irrigation water for rice cultivation all over the delta. In order to do this, the Chao Phraya Dam profoundly transformed the water flow pattern of the delta. Homan van der Heide's 1903 report stated that the most important purpose of the irrigation system was to maintain a constant flow of water as required by the expansion of rice cultivation. In his opinion, this could only be made possible by "perennial irrigation." Homan van der Heide contrasted perennial irrigation with the existing water infrastructure, which he referred to simply as the klong (canal in Thai) system. These canals were mostly for transportation and irrigation was merely a side effect. Homan van der Heide (1903) saw the irrigation function of the "klong system" as a primitive type of "inundation irrigation."

The main difference between perennial and inundation irrigation was found in the nature of water flow in the channels. In perennial irrigation, water constantly flowed through the channels from higher to lower places. Thus, it provided a constant flow of water to the fields. In contrast, inundation irrigation only provided such a sufficient flow during the rainy season when the river swelled and overflowed its banks. In this way, it was a technology that supported irrigation under circumstances of naturally occurring flooding. Furthermore, in contrast to perennial irrigation, inundation irrigation allowed water to flow in any direction, even from lowland to upland.

Living up to Homan van der Heide's vision, the Chao Phraya Dam has profoundly transformed the water flow of the entire delta. Before completion of the Chao Phraya Irrigation Project, the water flow in the delta was very complex and unruly because of its topography. In this extremely flat landscape, the floodwater in the rainy season spilled over the banks and stagnated in large areas of the delta, and the river and its distributaries occasionally flowed backwards due to high tides. Now the water of the Chao Phraya River System basically flows from upstream to downstream, from north to south, throughout the year. By damming the river flow at the top of the delta, the Chao Phraya Dam has raised the water levels of the upstream of the Noi, Tha Chin and the newly constructed Chainat-Pasak canal so that water in these channels flow smoothly downstream into networks of irrigation ditches. The dam thus enacts a certain 
type of land-water relation. It has transformed an unruly water flow into an ordered and stable one.

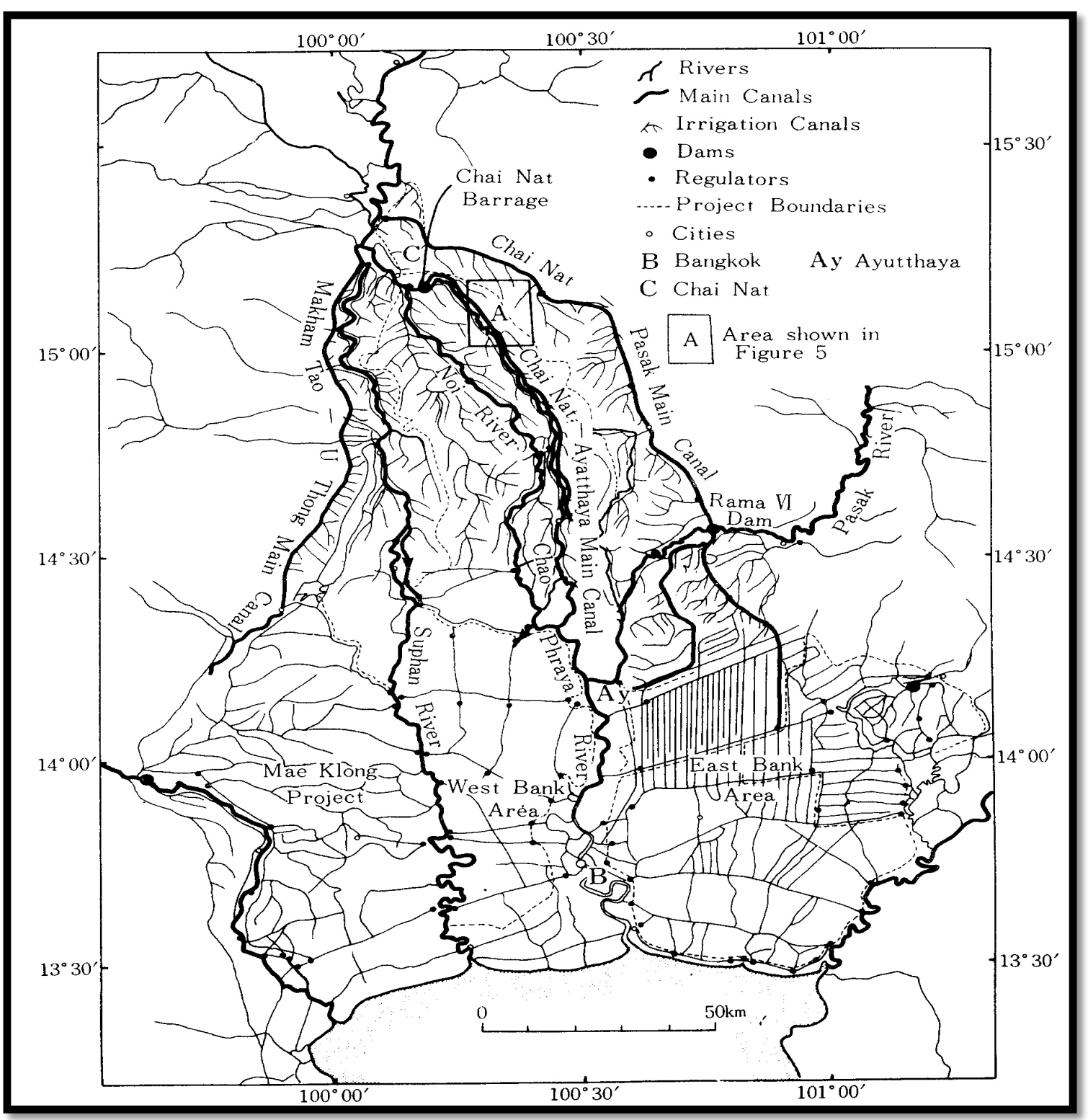

Figure 1: The Greater Chao Phraya Project (from Kaida 1978: 219) 
The Chao Phraya Dam epitomizes a high modern idea of river basin development. As François Molle (2009: 487) notes, the notion of drainage basin from the late 19th century to the early 20th century was mainly used to grasp the connectivity of river networks and the interaction between upstream and downstream. This interest was closely connected to the possibility of "conjunctive use of rivers for transportation, flood management [...] hydropower generation" and irrigation. At the end of the 19th century, British colonial engineers put this idea in practice in irrigation projects in the Indus and Nile river basins. These projects achieved enormous economic success for the colonial government at the time (Headrick 1988; Molle 2009). Not so surprising, Homan van der Heide (1903) used the Nile basin development as the main reference point for his design.

However, when I visited an irrigation office in Ayutthaya Province about 55 years after its mid-century completion, the system did not seem to enjoy such a reputation anymore. The office was in charge of allocation of water for an area roughly of district size and located on the edge of a low-laying, flood-prone area. After interviewing a group of people on flood management, one of the officers expressed his perplexity about my interest:

It is not a cutting edge system! There are not so many interesting things here (in the Chao Phraya system). You see, farmers have to pump up water from canals here because we don't have on-farm systems. If you want to see interesting things, you should go to latest irrigation systems in, for example, the Northeast Region. These newer systems are gravitational systems. It delivers water to each field through well-arranged on-farm systems.

To my surprise, it was not the last time I encountered such comments. Several irrigation officers I met regarded the Chao Phraya system as obsolete and of little technical interest.

Indeed, technical reports by development agencies often saw the Chao Phraya system as an incomplete system because of its lack of "on-farm" systems, networks of terminal irrigation channels that deliver water to individual plots (World Bank 1977). Although the Chao Phraya system is a successful perennial irrigation system that delivers water throughout the year, some irrigation engineers argue that the system is not complete as a full-fledged gravitational system because of its failure to deliver water directly to the fields. In gravitational systems, water is delivered by the constant and uniform force of gravity, rather than by the ad-hoc pumping efforts of individual farmers. Thus, it functions like a carefully built machine driven by the universal force of gravity.

Despite these kinds of criticism, the aesthetics of these irrigation engineers were well aligned with Homan van der Heide's vision of a Century ago, which saw perennial irrigation as the supreme form of irrigation. Both emphasize the constant flow of water, driven by the uniform force of gravity, as the central feature of modern irrigation. Moreover, this aesthetics matches well with that of hydrological models, the major tool by which hydrologists and irrigation managers estimate and predict water flows. These models have evolved through longstanding efforts to estimate the relationship between rainfall and river discharge to predict the size and timing of river flow increases from precipitation in the basin (Clifford 2011). 
Prediction of river discharge can be done either by statistical reasoning or by physically based modeling. While the former is based on the statistical relation between observed rainfall and river discharge, the latter depends on a calculation of hydraulic dynamics in the drainage basin (Todini 2011). Water flow is calculated from basic fluid dynamic equations, in which complex interactions between gravity and resistance are major forces. Although one can complicate these models indefinitely by adding intensive rainfall, tidal effects and inundation models, they are fundamentally based on the force of gravity that drains water from upland to the sea.

The correspondence between perennial irrigation design and the concept of the drainage basin is indicative of the tangled relation between science and water management infrastructures. For one thing, the development of the concept of the drainage basin was itself deeply embedded in water management infrastructures such as irrigation systems. It is no secret to hydrologists that the measurement of water flow in drainage basins depends on water management infrastructures (Clifford 2011). These infrastructures include networks of measuring devices such as river discharge and rain gauges. Such devices are usually installed with other technologies such as sluice gates and dams. Further, the hydrological efforts to calculate the relationship between rainfall and river discharge is tightly tied with engineering endeavors such as the design of sewers to drain floodwater from urban areas (Todini 2011). In this sense the scientific notion of drainage basin, the major conceptual device to capture the rainfall-river discharge relation was deeply entangled with engineering efforts to design infrastructure to drain water from the beginning.

Here we can begin to see the dual function of the drainage basin as a machine. On the one hand, perennial irrigation systems are huge machines driven by gravity to deliver water to fields. On the other hand, the notion of drainage basin embedded in this machine eventually became a theory machine that allowed hydrology to grasp the relations between land and water. After some time, as I continue to discuss, this theory machine stimulated further reflections on the earthly world.

\section{The Drainage Basin as the Fundamental Unit of Landform}

The emergence of the newly ordered flow in the Chao Phraya Delta also corresponded with the growing influence of the drainage basin beyond the boundaries of hydrology. Several years after the completion of the dam, the drainage basin emerged as "the fundamental geomorphic unit" (Chorley 1969: 75).

While the hydrological and geographical importance of the drainage basin had been long recognized (Clifford 2011), an influential review essay by Richard Chorley (1969) marked an emergent consensus among geomorphologists, geographers and hydrologists about the centrality of the drainage basin as a unit of analysis. According to Chorley, the importance of the drainage basin rests on an understanding of the driving forces in the formation of landforms. Modern geomorphology understands various landforms such as plains, valleys and mountains to be made by erosion of large rocky landmasses by water, wind and geo-chemical processes. The 
sediments created by erosion are transported by run-off of rainwater to lower places and eventually gather in a river. The river then transports sediments to estuaries where the sediments settle in shallows and gradually form an alluvial plain. In this framework, the drainage basin acts as the integral unit within which not only hydrological processes but also various land forming forces interact with each other, creating a variety of landforms, from mountain slopes to valleys and plains (Chorley 1969).

For geomorphology, in other words, the fundamental appeal of the drainage basin is its capacity to frame the physical interactions that shape landforms. It provides an explanation of landforms based on laws of physics. Until World War II, the study of landforms was predominantly descriptive and there was no unified scientific explanation of their formation. In this context, the concept of the drainage basin became attractive because it offered a general explanatory framework (Chorley 1969). Scientists came to conceive of drainage basins as a kind of universal machine that, by combining land-water interactions such as erosion, transport and sedimentation, could generate every known landform. Just like water infrastructures such as irrigation and sewer systems, this machine is driven by the universal force of gravity that drain water from upstream to the sea.

This view tied hydrology and geomorphology together as partners in a scheme to develop a unified science of earth surface processes. The entire surface of the planet could now in principle be divided into drainage basins. Since its establishment as the fundamental unit of landform, the drainage basin has exhibited a surprising capacity to connect diverse practices. Indeed, the concept has gained prominence in diverse fields, from the ecological sciences, to environmental management, engineering and urban design.

Notably, since the 1980s, it has been argued that environmental management should be based on drainage basins, rather than on national or administrative boundaries, which are arbitrary from a scientific viewpoint. Accordingly, the drainage basin has become a central framework in new approaches to environmental management such as Integrated Water Resource Management (IWRM) (Calder 2005; Newson 2009). From this point of view, the advantage of the drainage basin is to make it possible to conceive of integrated approaches to water flow, land use, biodiversity conservation, economic planning and infrastructural design.

Through the institutionalization of watershed management, taking such forms as river basin committees, watershed development projects, and basin wide infrastructures, drainage basins have gradually and quietly become a part of our collective life. In this ever-expanding context, the drainage basin began to exhibit its capacities as a theory machine by revealing hitherto unseen relations not only in rivers but also outside them.

\section{From Channel Network to the Entire Catchment}

On a planet divided into drainage basins, practically everything on the earth is seen as connected to everything else by flows of water. The emergent field of river basin ecology, a consequence of the introduction of the notion of drainage basin to the field of ecology, has revealed that the drainage basin "acts as an interconnected network of habitats for the biota of the basin, whose 
diversity and resilience provide goods and services to human societies within and outside its boundaries" (Newson 2009: 20, emphasis in the original). Interestingly, this extensive connectivity brought about a critical reappraisal of the water infrastructure designs that originally nurtured the development of the notion of drainage basin itself.

Since the 1990s, growing concerns over the environmental degradation of rivers running through urban regions has stimulated an expansion of research on the impact of urban environments on rivers, alongside increasing efforts to restore streams. Based on the notion of drainage basin as a hydro-ecosystem, scientists have examined the impact of land-surface changes—such as the transformation of grasslands to paved urban streets and housing areas-on river ecosystems.

What they discovered was the so-called "urban stream syndrome," which describes an unfavorable influence of urban land use on river environments (Walsh et al. 2005). These findings focused on the impact of impervious land surfaces -- for example those covered by asphalt and concrete, which do not allow water to infiltrate into soil -- on riverine systems. Not only does water flows more quickly on asphalt and concrete surfaces, it also collects chemical pollutants, which leads to higher concentration of pollutants in the river. In addition, impervious surfaces as well as sewage- and storm-water drainages collect and move rainwater much faster than vegetated surfaces, leading to hydrographic patterns with more frequent and abrupt water rising events. In summary, rainwater in urban areas flows into adjacent rivers much faster, and in larger volumes, than in earlier rural times. Such flows cause significant disturbances to ecosystems and lead to decreases in biodiversity.

This is where one can begin to observe how the transformed notion of the drainage basin comes to counter-act existing infrastructural designs. As Molle (2009) notes, the earlier interest in the drainage basin tended to focus on river networks and on exploiting the full potential of the river flow. The drainage basin was thus basically imagined as a water channel network, not unlike the Chao Phraya Irrigation system itself. However, the emergence of the scientific notion of drainage basin has directed attention to the hydrological processes on the land surface. In particular, the development of river-basin ecology, along with emergent forms of integrated water management, has shifted the focus from river networks to complex hydro-ecological processes at the scale of the entire basin.

It has long been known that all rainfall does not flow directly into rivers. Some portion stays in the soil, some infiltrates the groundwater, some is consumed by plants and evaporates into the air and some is used by people. In order to study the entire hydrological cycle, it was thus necessary to integrate different measurements and modeling efforts specific to these different hydrological processes. The establishment of the drainage basin as the fundamental geomorphic unit facilitated the holistic monitoring of hydrological processes. Based on these developments, river ecologists are now able to assess the impact of basin-wide hydrological processes on river ecosystems. That "unnatural" urban hydrological processes taking place upon impervious surfaces and running through sewer networks became a new matter of concern was a consequence of these transformations.

Noticeably, this problem, originally identified by river ecologists, was quickly taken up 
by urban planners, architects and civil engineers. By the early 2000s, urban designers began to see the urban stream syndrome as a fundamental critique of urban design.

The cause of the hydraulic disturbances, impervious surfaces and sewer pipes, are central features of modern urban design (Shannon 2013). Sewers, for example, were developed as a solution to increasing public health problems in large cities. Before the installation of underground sewer pipes, urban streams and canals filled with human waste were serious health threats. Since one of the fundamental remedies of the urban stream syndrome is to remove pipe networks and impervious surfaces, this in turn poses fundamental infrastructural challenge for the modern hygienic city. In other words, the emergent interest in alternatives to sewage pipes implies that the well-being of other life forms should be taken as seriously as that of humans.

\section{Waterscape Urbanism and an Ecology of Urban Patchworks}

New responses to the urban stream syndrome can be seen to represent a wider shift in urban design. As the urban design principle has shifted from socio-economic function to ecological rationality, Paola Viganò (2013) notes that water flow has emerged as a central element in designing urban space and infrastructure. New collaborations between ecological scientists and urban designers therefore center on an emerging view of the city as a particular kind of watershed ecosystem characterized by a high proportion of impervious surfaces. This ecosystem is characterized by heterogeneity, since urban land can be seen as a patch-work of small-scale and diverse land use units such as pavement, buildings, bare soil and vegetation (Pickett, Cadenasso, and McGrath 2013). Ecological studies of cities thus focuse on "patch dynamics," the interaction among such heterogeneous patches, mediated by water flows.

In these emergent collaborations, the watershed has been adopted as a framework for integrating ecology with social sciences and design. In this way, the watershed model has not only shifted the attention of urban designers from solid- to liquid-based models it has also inspired a reconceptualization of the city as located within the larger socio-ecological system of the drainage basin (Thaitakoo and McGrath 2010).

This new vision of watershed urbanism presently enables urban designers to reimagine sustainable city futures. At the same time, this vision also introduces new temporal and spatial scales into urban design. In one sense, the demand to reduce impervious surface articulated by watershed models entails a reversal of the urbanization process. This has led urban designers to look both back in time and to geographically less developed areas, where modern infrastructural solutions have not been fully implemented. Aside from the history of major European cities, various forms of "indigenous water management" have thus become reference points for urban designers (Shannon 2013, McGrath 2013). Bangkok, which used to be known as a Venice of the East, represents one such indigenous, non-Western model.

However, the massive modern transformation of Bangkok, and the resulting co-existence of heterogeneous elements, has also made this city illustrative of another kind of dynamic model. Since the 1970s, it gradually became clear that the construction of terrestrial infrastructures, like roads and high rise buildings, fundamentally hindered the circulation of healthy water within 
Bangkok's existing canal network. Small canals were often cut or narrowed by landfill for road construction, and clogged with waste collected by rainfall. These clogged canals diminished drainage capacity and turned into health hazards. Sustaining water flow in these small canals therefore became an important issue that related simultaneously to flood management and public health. In other words, the intersection of Bangkok's often-chaotic modernization with the river ecology, and with traditional infrastructures, has turned the city into an experimental site for exploring dynamic interaction among heterogeneous urban patches.

Using terminology from the ecological studies of cities (Pickett, Cadenasso, and McGrath 2013), the Thai landscape architect Danai Thaitakoo and the New York based urban planner Brian McGrath has characterized the extended urban area of Bangkok as exemplifying "the dynamic liquid states of waterscape urbanism" (Thaitakoo and McGrath 2010: 37, emphasis in original). Rather than focusing on the urban center, their analysis presents the entire delta area, including agricultural fringes, as a unit of waterscape dynamism. From this viewpoint, Bangkok appears as a modern terrestrial urban infrastructure "superimposed on a wet rice cultivation landscape" (McGrath and Thaitakoo 2005: 45).

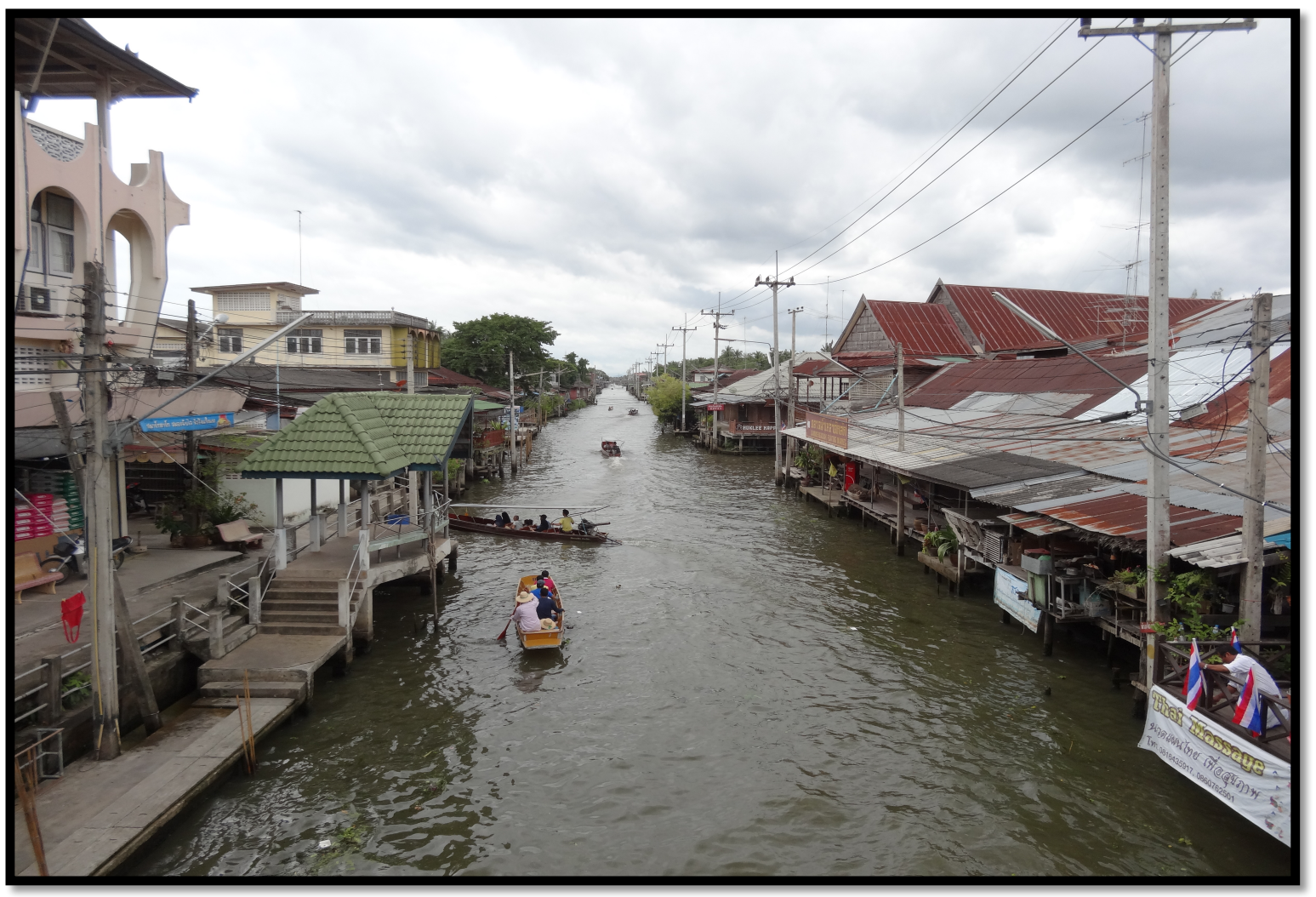

Figure 2: Amphibious townscape in the lower Chao Phraya Delta (photo by author) 
This patchy, heterogeneous landscape serves as a model for new watershed urbanism in two senses. On the one hand, traditional canal-centered townscapes found in the peripheral areas of Bangkok represent indigenous town planning adaptive to changing water. In these areas, flood adaptive houses on stilts sit along rivers and canals with irrigated orchid or paddy fields behind. During floods, these houses on stilts remain on top of the water. These amphibious townscapes have stimulated Thai, American and Japanese architects as a model for flood adaptive urban planning in the age of climate change (Thaitakoo and McGrath 2010, Morita 2015). Drawing on anthropological and area studies works on human-environment relations in the delta (Hanks 1972; Tanabe 1994; Takaya 1987), Danai and McGrath argue for the resilience of the traditional architecture and way of life.

Meanwhile, the entire watershed, composed of amphibious semi-agricultural periphery, terrestrial urban centers filled with high-rise buildings, industrial zones, and highway networks, serves as an experimental model for new ecological design. In this line of thinking, Bangkok's messy patchwork of semi-agricultural townscape and urban centers represents an interesting model for designing a sustainable patch dynamics. It is because of its incompleteness, as seen from a conventional urban planning viewpoint, that Bangkok and the Chao Phraya Delta can serve for envisioning future urban design. The irony is that this experimental model rests on the predicament of the city, which was brought about by the earlier rapid, and massive, terrestrial transformation. Far from intended, the current patchy nature of the city was an unintended consequence of the rapid, unplanned urban development.

For emerging forms of urban ecological design, the drainage basin works to reframe urban space from solid and terrestrial to fluid and amphibious (Thaitakoo and McGrath 2010, Shannon 2013). Rather than a machine for collecting and draining water, the drainage basin has been repurposed as a stage of various physical, chemical, biological, and social processes. These processes interact with each other in ways that cut across both scales and domains - such as the urban center and basin scales and ecology and architecture - sometimes to unforeseen effect. As many environmental experts now argue, the drainage basin offers a useful framework for foregrounding such unruly interactions (Calder 2005, Newson 2009; Pickett, Cadenasso, and McGrath 2013).

\section{Conclusion}

This paper has focused on the long and interwoven history of the scientific notion of drainage basin and the design of water infrastructures. In the early days, the concept of drainage basin was nested inside a mechanical vision of water infrastructures such as perennial and gravitational irrigation. Presently, initiatives to redesign urban infrastructures are nested inside the notion of drainage basin that enables the articulation of hidden flows and unexpected connections. Over a 50 -year period, figure and ground have reversed.

Behind this reversal sits both the conceptual development of the drainage basin as a 
figure of the universal landscape and the technological development of watershed monitoring and modeling, which is often embedded in water infrastructures. The emergence of the drainage basin as the fundamental geomorphic unit depended on both the analogy with water infrastructures, machines that drain water by relying on the universal force of gravity, and material entanglements with such infrastructures. In turn, the scientific notion of drainage basin as a machine for making landforms highlighted geomorphological and hydrological processes on land surfaces, eventually leading to an integration of the monitoring and modeling of these processes at the scale of drainage basin. The entwined developments of the drainage basin as a theory machine and water infrastructure as material machines have thus made it possible to conceptualize, test, and simulate complex interactions among hydrological, geomorphological, ecological and social processes. Through this development the drainage basin has come to enact a universal, though empirically variable, amphibious habitat, in which humans and non-humans cohabit within extensive relational webs mediated by water.

Alongside the transformation of the drainage basin, changes in the Chao Phraya delta exhibit an intriguing postcolonial inversion. Over the last 100 years, the role of the delta in relation to the global circulation of the notion of drainage basin has changed profoundly. At first, it was an unruly waterscape that needed to be subjected to the terrestrial imagination of Western engineering. Here, perennial and gravitational irrigation embodying the classic view of drainage basin played a normative role by enacting certain forms of land-water interaction. Presently, however, the delta has morphed into a messy, but also productive, experimental site for a new waterscape urbanism. The amphibious character of the delta, which before appeared as a problem, now turns out to be an advantage for thinking about urban futures in the era of climate change.

This future vision shares a central feature with other visions invoked by the drainage basin in recent years. The inaugural note of Watershed: People's forum on Ecology (1995), for example, argued that the watershed would help redefine social and economic development by bringing water-mediated connectivity to the fore. Similar to how Danai and McGrath see waterscape urbanism as an alternative to existing urban design, the note defines the watershed as a key for developing alternatives to the current extractive mode of development.

In turn, these visions parallel the renewed attention to water in STS and anthropology. As discussed in the introduction, these are fields in which water has offered metaphors for a range of theory developments. Advocates of such water metaphors often see the terrestrial imagination as deeply penetrating social scientific imagination and propose water metaphors as gestures toward alternative perspectives. Thus, just like watershed urbanism and development denote alternative futures, some authors argue that watery notions point toward alternative futures of social analysis.

Yet, these amphibious gestures in social science do not exactly match those in hydrology, water management and urban design. As I have shown, this is because the conceptual transformation in water science and technology has been tightly and materially connected with water infrastructures. This linkage that cut across the material and the conceptual hinges on the mechanical quality shared by the scientific notion and infrastructures. 
At the same time, amphibious developments within social science and water science and technology are not detached either. Watershed urbanism, for example, has mobilized anthropology and area studies of the Chao Phraya Delta while, in turn, the same social scientists have drawn upon Homan van der Heide's hydrological analysis as a significant source of inspiration (Takaya 1987; Tanabe 1994). Rather than running on parallel tracks water imaginations and metaphors are thus laterally entangled (cf. Morita 2014; Gad and Jensen 2016) across social and natural sciences.

This paper has followed these lateral connections, which cut across the boundary between the conceptual and the empirical, social and natural sciences. By doing so, it has focused on the wide-ranging connections that has produced and embodied the drainage basin. If the drainage basin, as a theory machine, is certainly "an object in the world that stimulates a theoretical formation" (Helmreich 2011: 132), I have shown that it is also more. The drainage basin is generative of new understanding of land-water interaction and of future visions precisely because of the very mechanical qualities that it gained through its historical entanglement with water infrastructures.

\section{Author Biography}

Atsuro Morita is associate professor of anthropology at Osaka University. He has done ethnographic research on hydrology and infrastructure development in Thailand and Japan focusing on how ideas, artifacts and people travel between the two countries and beyond. Together with Casper Bruun Jensen, he currently convenes the Japanese team of the Delta's Dealing with Uncertainty project. He is the author of Engineering in the Wild (Sekaishiso-sha, in Japanese), and editor of Infrastructures and Social Complexity: A Companion with Penny Harvey and Casper Bruun Jensen (Routledge, 2016).

\section{Acknowledgements}

This work was supported by JSPS KAKENHI Grant Number 24251017 and 15K12957, Open Research Area for the Social Sciences (ORA) co-funded by JSPS, ESRC, NWO and ANR. Earlier versions of this paper were presented at IT University Copenhagen, Stockholm University and University College London. I appreciate those who commented on my paper in these occasions. My thanks also go to Casper Brunn Jensen who commented on the paper and corrected my English.

\section{References}

Bakker, Karen. 2012." Water: Political, Biopolitical, Material." Social Studies of Science 42 (4): 616623.

Barnes, Jessica, and Samer Alatout. 2012. "Water worlds: Introduction to the special issue of Social Studies of Science." Social Studies of Science 42 (4): 483-488. 
Bijker, Wiebe. 2007. "Dikes and Dams, Thick with Politics." Isis 98 (1): 109-123.

Bijker, Wiebe. 2012. "Do we live in water cultures? A methodological commentary." Social Studies of Science 42 (4): 624-627.

Brummelhuis, Han ten. 2005. King of the waters : Homan van der Heide and the origin of modern irrigation in Siam. Leiden, Netherlands: KITLV Press.

Carse, Ashley. 2012. "Nature as infrastructure: Making and managing the Panama Canal watershed." Social Studies of Science 42 (4):539-563.

Calder, Ian R. 2005. Blue revolution : integrated land and water resource management. 2 nd ed. ed. London: Earthscan.

Chorley, Richard J. 1969. "The Drainage Basin as the Fundmental Geomorphic Unit." in Water, earth and man: a synthesis of hydrology, geomorphology, and socio-economic geography, edited by Richard J. Chorley. London: Methuen and Co.

Clifford, Nick. 2011. "Rivers and Drainage Basins." In The SAGE handbook of geographical knowledge, edited by John A. Agnew and David N. Livingstone. London: Sage.

Gad, Christopher and Casper Bruun Jensen. 2016. "Lateral Concepts." Engaging Science, Technology and Society 2: 3-12. doi: 10.17351/ests2016.77.

Galison, Peter. 2003. Einstein's Clocks and Poincaré's Maps: Empires of Time. 1st ed. New York: W.W. Norton.

Geertz, Clifford. 1972. "The wet and the dry: Traditional irrigation in Bali and Morocco." Human Ecology 1(1): 23-39,

Hanks, L.M. 1992. Rice and Man: Agricultural Ecology in Southeast Asia: University of Hawaii Press.

Headrick, Daniel R. 1988. The Tentacles of Progress: Technology Transfer in the Age of Imperialism, 1850-1940. New York; Oxford: Oxford University Press.

Helmreich, Stefan. 2011. "Nature/Culture/Seawater." American Anthropologist 113 (1):132-144.

Hesse, Mary. 1970. Models and Analogies in Science. Nortre Dame: University of Notre Dame Press.

Homan van der Heide, J. 1903. General report on irrigation and drainage in the lower Menam Valley. Bangkok: Ministry of Agriculture, Kingdom of Siam.

Kaida, Yoshihiro. 1978. Irrigation and Drainage: Present and Future. In Thailand : A Rice-Growing Society, edeted by Yoneo Ishii, 205-245. Honolulu: University Press of Hawaii.

Krause, Franz and Veronica Strang. 2016. "Thinking Relationships Through Water." Society $\mathcal{E}$ Natural Resources 29 (6): 633-638.

Leach, Edmund. 1954. Political Systems of Highland Burna. London: G. Bell \& Sons.

Maurer, Bill. 2004. Mutual Life, Limited. Princeton: Princeton University Press.

McGrath, Brian. 2013. "Slow, Moderate, Fast: Urban Adaptation and Change." In Resilience in ecology and urban design : linking theory and practice for sustainable cities, edited by Steward T. Pickett, Mary L. Cadenasso and Brian McGrath, 231-252. Dordrecht ; London: Springer.

McGrath, Brian, and Danai Thaitakoo. 2005. "Tasting the Periphery: Bangkok's Agri- and Aquacultural Fringe." Architectural Design 75 (3):43-51.

Molle, François. 2009. "River-basin planning and management: The social life of a concept." Geoforum 40 (3):484-494. 
Morita, Atsuro. 2014. "The Ethnographic Machine: Experimenting with Context and Comparison in Strathernian Ethnography." Science, Technology \& Human Values 39 (2):214-235.

Morita, Atsuro. 2016. "Infrastructuring Amphibious Space: The Interplay of Aquatic and Terrestrial Infrastructures in the Chao Phraya Delta in Thailand." Science as Culture 25 (1):117-140.

Newson, Malcolm David. 2009. Land, water and development : sustainable and adaptive management of rivers. 3rd ed. ed. London: Routledge.

Pickett, Steward T., Mary L. Cadenasso, and Brian McGrath. 2013. Resilience in ecology and urban design : linking theory and practice for sustainable cities. Dordrecht; London: Springer.

Shane, D. Grahame. 2013. "Urban Patch Dynamics and Resilience: Three London Urban Design Ecologies." In Resilience in ecology and urban design : linking theory and practice for sustainable cities, edited by Steward T. Pickett, Mary L. Cadenasso and Brian McGrath, 131-161. Dordrecht ; London: Springer.

Shannon, Kelly. 2013. "Eco-engineering for Water: From Soft to Hard and Back." In Resilience in ecology and urban design: linking theory and practice for sustainable cities, edited by Steward T. Pickett, Mary L. Cadenasso and Brian McGrath, 163-182. Dordrecht ; London: Springer.

Takaya, Yoshikazu. 1987. Agricultural Development of a Tropical Delta : A Study of the Chao Phraya Delta. Honolulu: University of Hawaii Press.

Tanabe, Shigeharu. 1994. Ecology and practical technology : Peasant Farming Systems in Thailand. Bangkok: White Lotus.

Thaitakoo, Danai, and Brian McGrath. 2010. "Bangkok liquid perception: waterscape urbanism in the Chao Phraya river delta and implications to climate change adaptation." In Water Communities, edited by Rajib Shaw and Danai Thaitakoo, 35-50. Emerald Group Publishing Limited.

Todini, E. 2011. "History and perspectives of hydrological catchment modelling." Hydrology Research 42 (2-3):73-85.

Viganò, Paola. 2013. "Urbanism and Ecological Rationality." In Resilience in ecology and urban design : linking theory and practice for sustainable cities, edited by Steward T. Pickett, Mary L. Cadenasso and Brian McGrath, 407-426. Dordrecht ; London: Springer.

Walsh, Christopher J., Allison H. Roy, Jack W. Feminella, Peter D. Cottingham, Peter M. Groffman, and Raymond P. Morgan. 2005. "The urban stream syndrome: current knowledge and the search for a cure." Journal of the North American Benthological Society 24 (3):706-723.

Watershed: People's Forum on Ecology. 1995. “Editorial: Why Watershed?" Watershed: People's Forum on Ecology 1 (1): 2-3.

World Bank. 1977. Thailand: Chao Phya Irrigation Improvement Project II. East Asia and Pacific Regional Office of World Bank. 